\title{
A Decision-Aiding Approach for Residential PhotoVoltaic System Choice: An Application to the French Context
}

\author{
Fredy Huaylla, Lamia Berrah, and Vincent Cliville \\ Laboratoire d'Informatique, Systèmes, Traitement de l'Information et de la Connaisance, \\ Annecy le Vieux, France \\ \{huayllfr, lamia.berrah, vincent.cliville\}@univ-savoie.fr
}

\begin{abstract}
In the last decade the interest for electric production using PhotoVoltaic System (PVS) has strongly increased; namely for the citizen who is able to use roofs or personal surfaces to put in place such systems. For instance, the installed residential PVS capacity has grown to $550 \mathrm{MW}$ (Megawatt) in metropolitan France during the last years. The same trend can be noticed in many developed countries at the same time. However, in light of this investment, people would like to be informed of the different aspects, especially the economic and environmental ones, in order to make their choice. In this sense, this paper deals with the decision-making problem for the residential PVS investment. Different alternatives of module surfaces and PV technology installation are considered and a procedure founded on the ELECTRE approach to aid the citizen in his choice is proposed.
\end{abstract}

Keywords: PhotoVoltaic System, sustainability, energy efficiency, DecisionAiding, ELECTRE.

\section{Introduction}

Nowadays in different countries, concerns about the environment are taken into account increasingly through energy policies that aim to reduce in the future the effects of the global warming generated by the emission of GreenHouse Gases (GHG). In Europe for example, the European Union (EU) has set as a goal for 2020 the production of $20 \%$ of its total consumed energy using Renewable Energy Systems (RES), which would imply a $33 \%$ electricity production coming from these kinds of systems [1]. In France, the goals mentioned above would imply a $23 \%$ total energy consumed production coming from RES [1]. To achieve this, during the last years French energy policies have promoted the installation of PhotoVoltaic Systems (PVS) mainly through solar plants and residential PVS. As a result, at the end of March 2011, 1146 MW had been installed in metropolitan France, where about half corresponded to residential PVS (integrated into the buildings) [2].

From a general point of view, a PVS is a system composed of PhotoVoltaic (PV) modules and other complementary components called Balance of System (BOS). BOS includes: structures for mounting the modules and the power-conditioning equipment for converting the generated direct current electricity (DC) into alternating 
current electricity (AC), with the required form and magnitude for its consumption or insertion in the power grid [3]. PV modules are usually made of mono-crystalline silicon (sc-Si), multi-crystalline silicon (mc-Si) and amorphous silicon (a-Si). The solar energy to electricity conversion yield of each module usually goes in the following order, starting from the bigger: sc-Si, mc-Si and a-Si [4].

Since the installation of a PVS implies an investment, it is logical to compare these kinds of projects with other options. Different criteria are associated to PVS, such as energy, economics, environmental and social criteria, where each criterion has different indicators that can permit an assessment of the performance of the whole system. To cope with such a decision problem, studies have already been made to find the best renewable energy system including PVS. For example, Hauran et al. [1] used a multicriteria-aiding decision method to select the 4 best PVS projects among 16 projects that were presented to the local government of the island of Corsica in France. For that assessment, 7 criteria have been considered, related to energy, environmental, social and economic aspects, such as: total energy produced, ecological degradation, economic and financial benefits to the community, visual impact, etc. In general, the point of view of the evaluation was one that looked for the benefit to the whole community, so economic aspects related to the profitability of the project were not taken explicitly into account [1]. Athanasios et al. [5] assessed 10 power plants considering technological, economic and sustainability aspects through 9 criteria. The ranking of the project is obtained after the application of the AHP Analytical Hierarchy Process - method. In their study, an emphasis was put on technology and sustainability criteria, giving the conclusion that renewable energy plants were at the top of the evaluation ranking. Again, economic criteria did not consider the profitability of each plant; instead, investment and operational costs were taken into account [5].

If the previous works concern public organisations decisions, they do not have an equivalent for the private investors and particularly for residential investment. In this study, a decision-making problem related to French residential PVS is studied considering energy, economic, environment and esthetic criteria. As a difference from cited works, the profitability of the PVS was taken into account in the economic criteria since, in our case, the considered point of view is the one of an investor (the owner of the dwelling), who, logically, would like to recover his investment. More precisely, for a given location, people of residential sectors willing to produce electric energy by investing in a PVS are faced with the following problem: Which kind of technology to choose among the three available on the market and what is the total surface to put in place? Knowing the involved criteria for choosing the PVS, this is a typical multicriteria decision problem of potential alternatives ranking. So using MultiCriteria Decision Aiding (MCDA) methods, namely the outranking ones, can supply interesting information to aid residential people in their choice.

This paper is organised as follows. In Section 2 the French context related to residential PVS systems is summarised. In Section 3 the decision problem is described by the considered alternatives and criteria. Then the ELECTRE III (ELimination and Choice expressing The Reality) outranking method is used to rank the alternatives. Results are discussed before concluding remarks. 


\section{French Policy for Residential PVS}

Since 2004, the number of PVS installations in France has grown thanks to the implementation of a tax credit for the material costs of the systems. Since 2006 this increase is higher because of the policy implementation in tariffs that obligates the French electricity company, Électricité de France (EDF), to buy and to pay for the electricity produced by PVS. As a consequence, at the end of March 2011, residential PVS represented more than $550 \mathrm{MW}$ distributed in more than 160000 installations of less than 10kWp, where $98 \%$ had a nominal power of less than $3 \mathrm{kWp}$ [2].

Nowadays, French PV policy is maintained although the level of subsidies has been reduced compared to previous years. The policy for residential PVS can be summarised in the following points [6] [7].

- Residential PVS installations of less than $9 \mathrm{kWp}$ can enjoy of a tax credit of $11 \%$ for the material cost of the system.

- EDF company signs a contract with the owner to buy the electricity produced by the PVS. The tariff is fixed for 20 years at the moment of the contact signing. At the second trimester of 2012 , this tariff was $0.3706 € / \mathrm{kWh}$ for installations of a peak power under $9 \mathrm{kWp}$.

- A Value Added Tax (VAT) of 7\% is applied for the material and installation costs for residential PVS of less than $3 \mathrm{kWp}$; although, the TVA rises up to $19.6 \%$ for PVS installations of over $3 \mathrm{kWp}$.

- Local governments usually give financial aids for the PVS installation.

Our studied residential PVS are located in the Rhône-Alpes area in France. We assume the valid PV policy in 2012 and the following considerations.

- The PVS accomplishes all the technical constraints required to benefit from the subsidies.

- The solar irradiation over the PV modules, with a slope of $45^{\circ}$ and a South orientation, was set to $1408 \mathrm{kWh} / \mathrm{m}^{2} /$ year.

- The life time of the installation was set for 20 years.

- The discount rate over the investment was set at $3 \%$.

- The maintenance costs of the PVS were considered 0.

- The dwelling surface was equal to $80 \mathrm{~m} 2$ and the final annual energy consumption of a standard French dwelling equal to $137 \mathrm{kWh} / \mathrm{m} 2 /$ year [8].

So a citizen who is interested in installing a PVS on his dwelling roof can describe a given PVS, identified as its module technology and the total modules surface, through the considered criteria (energy, economic, environmental and esthetic) for the assessment study. Thus the possible alternatives can be compared in order to give information for the final choice. But this comparison can be difficult because there is often no Pareto dominance: how to know if a more economic PVS is more attractive than another which is better according to the environmental criteria? So for residential people, a ranking which gives a synthesising view of the potential PVS represents an interesting progress. In this way the MCDA outranking methods supply partial preorder of the potential alternatives [9], i.e. a ranking of the considered PVSs according to the preferences of the dwelling owner. 
Obviously, aggregation methods like MAUT, AHP, MACBETH or UTA could be used, each of which allows decision-maker to supply total order information [10], [11]. However, such methods need more knowledge to build the utility functions and so remain less understandable for residential investors than the outranking methods that directly use criteria values. The main outranking methods are the ELECTRE family [12] and the PROMETHEE family [13]. Interested readers can find the description of these methods in [14]. The ELECTRE III method which is well adapted to the real life company decision problems as shown by the numerous studies already published, is used in this study [15].

\section{Decision-Aiding for Residential PVS}

\subsection{Problem Definition}

The considered problem is viewed as a ranking problem, i.e. the residential investor would like to know what the best alternatives are. In this way it is necessary to define:

- the set of considered alternatives,

- the retained decision criteria,

- the description of each alternative according to the criteria.

Twelve alternative scenarios are considered for our decision problem. For working purposes, each alternative is labelled by the combination of the considered technology ( (sc-Si, mc-Si and a-Si) and the total module surfaces $\left(6.25,12.5,18.75\right.$ and $25 \mathrm{~m}^{2}$ ). For example: Alternative one = ALT1 = "sc-Si; $6.25 \mathrm{~m}^{2}$ ".

Six decision criteria are retained, which are:

- II, the Initial Investment, i.e. the amount of money required at the beginning for installing the PVS.

- $P I=\frac{N P V}{I I}$, the Profitability of the Investment at the end of the system's life cycle, defined as, with $N P V$ : Net Present Value [16].

- $E R=\frac{A E P}{A E C}$, the Energy Ratio, with $A E P$ : Annual Electricity Production of the PVS, AEC: Annual Energy Consumption of the dwelling.

- $E P B T=\frac{P E}{A E P}$, the Energy Payback Time with $P E$ : Primary Energy used by the PVS during its whole life cycle, AEP: Annual Equivalent Primary Energy produced by the PVS [3] [4].

- $G H G=\frac{E G E}{T P E}$, the normalised equivalent emissions with $E G E$ : Equivalent Grams (of $\mathrm{CO}_{2}$ ) Emitted during the whole PVS life cycle, TPE: Total Produced Electricity during the whole PVS life cycle. [3] [4].

- Esthetic, related to the visual impact of the PVS. 
The values associated to each criterion for the considered alternatives are given in table 1. They are computed using data from previous works and from current legislation and costs. In this sense for example, values for EPBT and $G H G$ equivalent emissions are computed from studies made by Fthenakis and Alsema for different PV module technologies [3] [17]. Economic values are computed from current legislation [6] [7] and esthetic values are assigned considering a point of view of a selected potential investor.

Table 1. Criteria values

\begin{tabular}{cccccccc}
\hline \multicolumn{2}{c}{ Alternatives } & \multicolumn{7}{c}{ Criteria } \\
\hline Name & $\begin{array}{c}\text { Technology, } \\
\text { Surface }\left(\mathrm{m}^{2}\right)\end{array}$ & II $(€)$ & PI & $\begin{array}{c}\text { ER } \\
(\%)\end{array}$ & $\begin{array}{c}\text { EBPT } \\
\text { (years })\end{array}$ & $\begin{array}{c}\text { GHG } \\
\left(\mathrm{gCO}_{2} / \mathrm{kWh}\right)\end{array}$ & $\begin{array}{c}\text { ESTH } \\
(1-7)\end{array}$ \\
\hline ALT1 & sc-Si, 6.25 & 3719 & -0.33 & 9.1 & 3.0 & 75.6 & 7 \\
ALT2 & mc-Si, 6.25 & 3315 & -0.23 & 9.2 & 2.3 & 58.1 & 6 \\
ALT3 & a-Si, 6.25 & 2701 & -0.43 & 7.5 & 1.9 & 50.4 & 5 \\
ALT4 & sc-Si, 12.5 & 7187 & 0.05 & 18.2 & 3.0 & 75.6 & 7 \\
ALT5 & mc-Si, 12.5 & 6380 & 0.2 & 18.3 & 2.3 & 58.1 & 6 \\
ALT6 & a-Si, 12.5 & 5152 & 0.09 & 14.9 & 1.9 & 50.4 & 5 \\
ALT7 & sc-Si, 18.75 & 10656 & 0.18 & 27.3 & 3.0 & 75.6 & 7 \\
ALT8 & mc-Si, 18.75 & 9446 & 0.35 & 27.5 & 2.3 & 58.1 & 6 \\
ALT9 & a-Si, 18.75 & 7603 & 0.27 & 22.4 & 1.9 & 50.4 & 5 \\
ALT10 & sc-Si, 25 & 15759 & 0.11 & 36.3 & 3.0 & 75.6 & 7 \\
ALT11 & mc-Si, 25 & 13955 & 0.27 & 36.7 & 2.3 & 58.1 & 6 \\
ALT12 & a-Si, 25 & 9530 & 0.49 & 29.9 & 1.9 & 50.4 & 5 \\
\hline
\end{tabular}

It appears that there is no alternative which is better or less equal to the others according the whole set of criteria (no Pareto dominance). Thus, it is not possible to make a choice from this information. The ELECTRE III method is hence deployed to give more meaningful information.

\subsection{ELECTRE III Method}

From the alternatives description, ELECTRE III ranks the set of alternatives by considering pairwise comparisons according to the Condorcet principle which announces that an alternative outranks another one if it is at least as good according to a majority of criteria without being clearly worst according to the other criteria [18]. The preference relation definition between two alternatives is based on the concordance index which reflects the arguments to favour a given action instead of another one and the discordance index which reflects the argument against this action instead of this other action. The computation of these indexes involves the definition of both criterion preference thresholds and criterion weights representing the criterion's relative importance in the decision-making process. The comparison of the whole pairwise comparisons thanks to mathematical rules allows to give as a final result a partial preorder of the alternatives. Interested readers can find more detailed 
information in [9] [15]. Note that complementary sensitivity analysis of the description of actions or criteria (thresholds, weight) can be made to reinforce the information for decision-aid.

\subsection{ELECTRE III Parameters Definition}

To proceed with the ELECTRE III software which supports the method, the preference thresholds of indifference and strict preference have to be expressed for each criterion. These values are assigned by the dwelling owner thanks to a dialogue with the ELECTRE method expert who has to explain the meaning of the parameters. The weight definitions of the 6 considered criteria are obtained by the SIMOS method [19]. Both declared thresholds and weights are found in table 2.

In addition, ELECTRE III deployment requires quantitative values for all the criteria, which is not the case for the esthetic criterion. So, linguistic terms must be converted into quantitative values. This transformation leads to integer values that increase with the satisfaction level (a scale from 1 to 7 is retained). Two integers associated to two successive linguistic terms must be different according to the considered strict preference threshold, so the concordance index computation can be consistent.

Table 2. Weights and thresholds values

\begin{tabular}{ccccccc}
\hline & $I I(€)$ & $P I$ & $\begin{array}{c}E R \\
(\%)\end{array}$ & $\begin{array}{c}E P B T \\
(\text { years })\end{array}$ & $\begin{array}{c}G H G \\
\left(\mathrm{gCO}_{2} / \mathrm{kWh}\right)\end{array}$ & $\begin{array}{c}E S T H \\
(1-7)\end{array}$ \\
\hline Weight & 2.6 & 1.7 & 2.6 & 0.7 & 0.7 & 1.7 \\
Indifference threshold & $5 \% * \mathrm{II}$ & 0.05 & $5 \%$ & 0.5 & 1 & 1 \\
Strict pref. threshold & $10 \% * \mathrm{II}$ & 0.2 & $15 \%$ & 1 & 5 & 1 \\
\hline
\end{tabular}

\subsection{Results and Discussion}

The ranking of the alternatives is given in figure 1. The alternative "ALT12" is considered as better than all the other ones. The alternative "ALT5" is better than the other ones except "ALT12" and is incomparable with "ALT6. So a given alternative can be ranked with possibilities of ex-aequo (AlT4, ALT 9) or incomparability (ALT8, ALT 4). Hence, residential people can choose the "ALT12" alternative. To better assess this choice, they can also make a sensitivity analysis regarding:

- the ELECTRE parameters definition (weights and threshold),

- the values describing the alternatives according to the criteria.

The first sensitivity analysis must be carried out when the residential people have hesitated during the questionnaire allowing the ELECTRE deployment. It can also be interesting to simulate different types of people behaviour such as "mainly economic" with the high weight for PI, "mainly environmental" with high weights for EPBT and $G H G$ or for "limited investment capacity" with a high weight for II. 


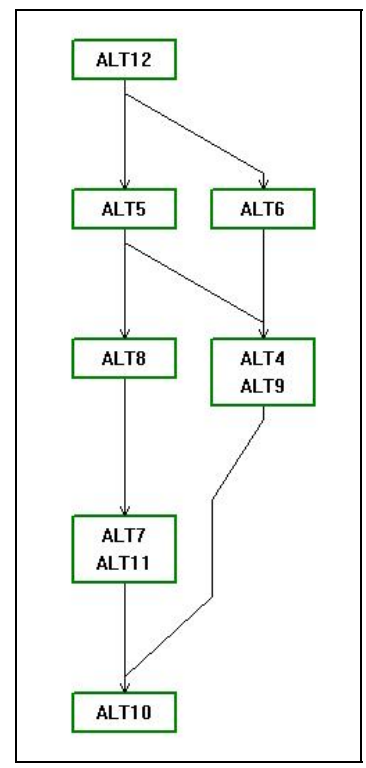

Fig. 1. Alternative partial pre-order obtained with ELECTRE

The second analysis is useful to take into account the potential uncertainties concerning the alternative description through the six criteria, namely the technical and economic ones. Indeed, it is well known that energy production depends on environmental factors and that the governmental tax policy can change during the twenty five years of PVS exploitation [20]. Besides the traditional indifference and strict preference thresholds definition, current works are in progress to deal with this point which can modify the initial ranking given in fig. 1. Main contributions of this work were the application of an outranking method to a PVS residential context and the consideration of direct economic benefits, such as the PI.

\section{Conclusions}

This study concerns the residential PVS choice. After a description of the PV module which is the main component of the PVS, the French PVS installation context is presented. From the review of criteria for PVS choice, the study focuses on relevant ones for residential installation. Then the decision-aiding ELECTRE method is briefly described before its application for the PVS residential choice among twelve alternative PVS. The obtained partial preorder is presented and discussed namely through the two complementary sensitivity analyses. Further works for taking into account uncertainties about technical and economic aspects are finally envisaged. Further works for taking into account uncertainties about technical and economic aspects are envisaged as well as the adaptation of the method for the use of PVS installers and resellers. 


\section{References}

1. Haurant, P., Oberti, P., Muselli, M.: Multicriteria selection aiding related to photovoltaic plants on farming fields on Corsica island: A real case study using the ELECTRE outranking framework. Energy Policy 39, 676-688 (2011)

2. Leloux, J., Narvarte, L., Trebosc, D.: Review of the performance of residential PV systems in France. Renewable and Sustainable Energy Reviews 16, 1369-1376 (2012)

3. Fthenakis, V.M., Kim, H.C.: Photovoltaics: Life-cycle analyses. Solar Energy 85, 1609$1628(2011)$

4. Sumper, A., Robledo-García, M.: Life-cycle assessment of a photovoltaic system in Catalonia (Spain). Renewable and Sustainable Energy Reviews 15, 3888-3896 (2011)

5. Athanasios, I., Petros, A.: Technological, economic and sustainability evaluation of power plants using the Analytic Hierarchy Process. Energy Policy 37, 778-787 (2009)

6. EDF ENR Énergies Nouvelles Réparties, http: / /www. edfenr.com/ le-photovoltaique/tarif-achat-et-credits-d-impotsphotovoltaiques-n799-1.aspx

7. ECOinfos Énergies Renouvelables, http://www. les-energies-renouvelables. eu/energies-renouvelables / 9702 toutes-les-aides-pour-realiserson-installation-photovoltaique.html

8. CYTHELIA, http://www. cythelia.fr/maison-zen.html

9. Roy, B.: Paradigms and Challenges. In: Figueira, J., Greco, S., Ehrgott, M. (eds.) Multiple Criteria Decision Analysis. State of the Art Surveys, pp. 3-24. Springer (2005)

10. Guitouni, A., Martel, J.M.: Tentative guidelines to help choosing an appropriate MCDA method. European Journal of Operational Research 109(2), 501-521 (1998)

11. Greco, S., Marques Pereira, R.A., Squillante, M., Yager, R.R.: Preferences and Decisions: Models and Applications, 430 p. Springer, Berlin (2010)

12. Roy, B.: The outranking approach and the foundations of ELECTRE methods. Theory and Decision 31, 49-73 (1991)

13. Brans, J.P., Mareschal, B., Vincke, P.: How to select and how to rank projects: The PROMETHEE method. European Journal of Op. Research 24(2), 228-238 (1986)

14. Martel, J.-M., Matarazzo, B.: Other outranking approaches. In: Figueira, J., Greco, S., Ehrgott, M. (eds.) Multiple Criteria Decision Analysis. State of the Art Surveys, pp. 197262. Springer (2005)

15. Figueira, J., Mousseau, V., Roy, B.: Electre Methods. In: Figueira, J., Greco, S., Ehrgott, M. (eds.) Multiple Criteria Decision Analysis. State of the Art Surveys, pp. 133-162. Springer (2005b)

16. Chabot, B.: TEC: an analysis economics method (La méthode TEC d'analyse économique). Energy economics cours, Polytech Annecy-Chambéry, France (2012)

17. Alsema, E., de Wild-Scholten, M.: Environmental impact of crystalline silicon photovoltaic module production. In: Material Research Society Fall Meeting, Symposium G: Life Cycle Analysis Tools for "Green" Materials and Process Selection, Boston, MA (2005)

18. Condorcet, J.A.M. Caritat, Marquis De: Essai sur l'application de l'analyse la probabilité des décisions rendues. la pluralité des voix, Imprimerie Royale, Paris (1785)

19. Figueira, J., Roy, B.: Determining the weights of criteria in the ELECTRE type methods with a revised Simos' procedure. Eur. J. of Operational Research 139, 317-326 (2002)

20. Huaylla Roque, F.: Les sytèmes photovoltaïques: caractéristiques et performance, Master Thesis, Université de Savoie, 52 p. (2012) (in French) 